\title{
The Art Therapy Experiences of Patients and Their Family Members in Hospice Palliative Care
}

\author{
Sungeun Park, Ph.D. ${ }^{*}{ }^{\dagger}$ and Hyunjoo Song, Ph.D. ${ }^{\dagger}$
}

*Department of Expressive Art Therapy, The Graduate School of Professional Therapeutic Technology, Seoul Women's University, ${ }^{\dagger}$ Hospice Palliative Care Center, Seoul Medical Center, ${ }^{\dagger}$ Department of Psychotherapy, The Graduate School of Professional Therapeutic Technology, Seoul Women's University, Seoul, Korea

Purpose: In this study, the researchers closely investigated the psychosocial problems faced by terminal cancer patients and their family members in hospice palliative care units. Methods: The investigators conducted four sessions of art therapy intervention programs for the terminal cancer patients and their family members, carried out in-depth interviews about the influence of the cancer experience on their family function and quality of life, and analyzed their experiences using grounded theory methodology. Results: After providing autonomous written informed consent, six pairs of terminally ill cancer patients and their family members, accounting for a total of 17 participants with the inclusion of additional family members who took part sporadically, took part in the art therapy intervention and interviews. The raw data, in the form of verbatim records, were analyzed according to the procedures of grounded theory (open, axial, and selective coding). Through these processes, a total of 154 concepts, 56 subcategories, and 13 categories were identified. Families were classified into four types according to their family function, quality of life, and attitude toward death. Though the art therapy intervention, patients and their family members experienced three stages over time. Conclusion: This research focused on essential aspects of the family relationships and the art therapy experiences of terminal cancer patients and their family members through an art therapy intervention in the context of hospice palliative care. Based on these observations, the researchers constructed a theoretical rationale for art therapy interventions delivered to patients and their family members in the process of hospice palliative care.

Key Words: Hospice care, Palliative care, Art therapy, Grounded theory, Patients, Caregivers, Quality of life
Received March 28, 2020

Revised September 10, 2020

Accepted October 30, 2020

\section{Correspondence to}

Hyunjoo Song

ORCID:

https://orcid.org/0000-0002-7199-6461

E-mail: jayoo1004@swu.ac.kr

This work is a revision of the first author's doctoral dissertation from Seoul women's university.

\section{INTRODUCTION}

\section{Background}

From birth to death, human beings do not live alone, and regular interactions with family members profoundly shape humans' lives. Life-threatening illnesses such as cancer often destabilize family systems and lead to changes in family relationships, roles, and communication. While some families adapt well to the crisis and maintain their functions, others go through hard times of maladaptation [1]. The issues faced by cancer patients are not only their own, but also impact the 
entire family, so it is important to deal with issues of both patients and their family.

In the healthcare sector, quality of life has recently been added as an indicator for evaluating health status, in addition to clinical parameters such as survival and mortality rates. Some studies reported that the quality of life of family members affected patients' quality of life [2], and that consistent problemsolving and handling of issues influenced the quality of life of patients and their family members [3]. Programs should be developed to provide psychological interventions on the physical, social, emotional, and spiritual issues of terminal cancer patients and their families and to facilitate interactions for improving their quality of life, based on a study demonstrating that patients' quality of life is connected to that of their family members and that along with the patients' level of activity and economic factors, caregivers' perceived family function can have an impact on patients' quality of life [4].

Psychosocial care in the medical environment deals with the cognitive, emotional, and social needs of the patients and supports, restores, and enhances patients' growth. Art therapy helps patients and their family members improve self-awareness, cope with their symptoms, and overcome their stress and psychological shock [5]. In particular, artwork helps patients express themselves at a time when it is difficult to verbalize their experiences of suffering, confusion, and contradictory experiences of life, and also helps provide social support for family members and caregivers [6]. Art therapy for cancer patients reduced stress and symptoms, improved quality of life [7], and assisted patients communicate about the suffering caused by their illness, as well as providing emotional support and psychological well-being for family caregivers [8]. Korean research has suggested that art therapy improved communication between terminal cancer patients and their family members $[9,10]$. Walsh and Weiss in their art intervention therapy program "Art Infusion" suggested that collaborative artwork of cancer patients and families helped improve affirmative communication among family members [5]. In hospice palliative care, providing support for family members, as well as for patients, is a crucial component in the psychological care for terminal cancer patients $[9,10]$, so art therapy programs as a therapeutical approach to promote better communication between patients and family caregivers are needed. However, most earlier research focused on patients only, and scarcely studied the art therapy experiences of patients and their family members. An insufficient understanding of the psychological issues suffered by terminal cancer patients and their family members during art therapy sessions in hospice palliative care hampers appropriate support for patients and caregivers; therefore, comprehending the experiences of patients and their family members as a whole is of paramount importance.

The purpose of this study was to understand the disease experiences that affect the dynamics between the patient and their family members and to observe how experiences of art therapy influence family function and quality of life, while formulating a theoretical foundation of art therapy for terminal cancer patients and their family members in hospice palliative care. This study was also intended to lay the groundwork for art therapy in hospice palliative care by investigating the role of art therapy as a psychological intervention for terminal cancer patients and family caregivers.

\section{Purpose}

The purposes of this study were:

First, to investigate how the experiences of struggle against illness or caregiving of patients and their family manifested in art therapy in hospice palliative care.

Second, to investigate how a short-term art therapy intervention affected the quality of life and family function of terminal cancer patients and their family members.

\section{Theoretical framework}

\section{1) Art therapy in hospice palliative care}

Most terminal cancer patients face physical, psychological, social, and spiritual issues. Hospice palliative care aims to help patients achieve the best possible quality of life instead of providing futile treatment [11]. Although physical symptoms can be controlled with drugs, patients often find themselves losing control of their emotions as they enter the final stage of their life, accompanied by the fear of death and facing tremendous challenges, which often cause depression [12].

The principal goal of art therapy in the medical setting is to deal with and improve the psychosocial care. The purpose of psychosocial care is to support and enhance patients' growth and recovery by dealing with patients' cognitive, emotional, 
and social needs, while focusing on psychosocial aspects and their emotional growth and development [5]. Art therapy is a clinical intervention based on the conviction that the creative process involved in art therapy can help to heal patients, to improve their life, to enhance their self-awareness (and that of their family members), to cope with symptoms, and to adapt to a situation full of stress and shocks [13]. Art therapy helps to reduce the physical pain of patients and provide them with an opportunity to express their unstable emotions, so that they can relieve tension and feel well-being when going through spiritual and emotional hardship [14]. Malchiodi defines clinical art therapy in the hospital setting as "using art therapy for people who went through active medical treatment such as surgery or chemotherapy, disease, or physical injury”. Expression through artwork is especially useful when people find it difficult to verbalize the pain, confusion, and conflict of being ill, as it helps cancer patients express their feelings and experiences, as well as providing social support during the medical treatment and recovery process for caregivers, family, and colleagues, with whom they need to maintain relationships [6].

Art therapy in hospice palliative care involves a holistic approach that can improve patients' quality of life in their final stages of life. Patients can gain a sense of confidence and $\mathrm{ac}^{-}$ complishment by completing artwork using media and choosing themes by themselves. Such experiences helped them realize that they can maintain their human dignity as productive adults even at the end-stage of life, and recognize that they are still persons of worth despite their illness [12]. The key purpose of creating artwork at the end of life is "meaning-making" [6]. "Meaning-making" is a creative process focused on restoring meaning, metaphorical conversation, and commemoration, during which art making allows patients to accept their emotions naturally at a transitional period and facilitates acceptance of their diverse feelings through the creative process [15]. In particular, art therapy enables people to understand the psychological dynamics caused by loss and serves as an outlet to realize the meaning of their past lives and express their missed opportunities. The images created during art therapy become a medium for expression and healing by helping the individual reflect upon the episodes of his or her life [16].

Most people facing death wish to have the opportunity to reflect upon and reevaluate their lives and leave a legacy for their family and friends. Sharing their thoughts on how they would like to be remembered after death will also be helpful for their family members after bereavement. Art therapy helps patients deal with their difficult feelings so that they can define their emotions and cope with their worries, providing them with time to share memories with friends and family, reflect on their life, and conclude any issues that need to be resolved before death [12]. Art therapy in hospice palliative care helps the bereaved family to form 'continuing bonds' with the patient even after death through the process of creating tangible artwork that lasts after death, thereby assisting the family in coping with loss and bereavement [17]. The process of art therapy provides psychological support and resources for the bereaved family to maintain connection with the deceased, rather than completely separating with him or her even after the loss. A sincere farewell between the patient and family members at the last stage of life also provides psychological resources for the loved ones to move on with their lives comfortably [18]. Art therapy is an intervention that can help terminal cancer patients and their family members, who are faced with an existential crisis, learn to accept the process of death and develop a more flexible view by moving beyond their initial unstable emotional state, connecting with family members and medical staff, and building a relationship with the therapist to improve self-expression, meaning-making, and quality of life [18].

Family members can be involved in art therapy during $\mathrm{pa}^{-}$ tients' art therapy sessions. Patients enhance the creativity of the family members and interact with their family and their own art work, while the family takes part in caregiving [19].

In recent years, art therapy programs have advanced greatly in Korea's hospice palliative care units and various forms of art therapy have become a "must" to improve the quality of life of patients through the enforcement of the Act on Decisions on Life-Sustaining Treatment for Patients in Hospice and Palliative Care or at the End of Life. Providing support for both patients in hospice palliative care and family members is essential to provide psychological care for terminal cancer patients. Art therapy programs should be developed as a treatment approach to improve communication between patients and their family members. This study aimed to develop an appropriate art therapy intervention program based on an understanding of the psychology of the family members of terminal cancer 
patients and family function.

\section{METHODS}

\section{Study design}

This study developed an art therapy intervention program designed to improve family function and quality of life by interviewing patients admitted to hospice palliative care units and their family members using the grounded theory method to understand patients' and family members' experiences of participating in art therapy. Grounded theory is a type of onsite research conducted in hospitals, outpatient clinics, and nursing homes that involves observing phenomena in a natural setting and constructing hypotheses and theories by collecting data from the behaviors, interactions, and social processes of people on site. Grounded theory is a qualitative research framework that seeks to identify the essential aspects of patients' and family members' experience, and is therefore suitable for consultations and treatments that identify various underlying causes and offer therapeutic approaches.

The researchers in this study used an art therapy program constructed based on previous studies of art therapy for terminal cancer patients and the elderly. The program was carried out with careful consideration of the physical and psychological circumstances of patients admitted to hospice palliative care units and their family members.

\section{Participant selection and ethical considerations}

This study paired each patient admitted to hospice palliative care with a family member to understand their relationship and the dynamics of their art therapy experience. Participants were recruited from the hospice palliative care units of two city hospitals in Seoul. Approval was obtained from the Institutional Review Board of 'Seoul Medical Center' (IRB No. 2019-04-007-001), and participants were recruited from June to November 2019. Prior to the study, participants were referred by coordinators and social workers at each hospital, and the final participants comprised patients and their family members who provided informed consent after receiving an explanation of the content of the study. The researchers described the purpose and the content of the study, as well as the art therapy program, and informed participants that they could withdraw from the study any time and would not have any disadvantage by not participating. Participants were also notified that the process of artwork and the interview content would be recorded and collected and that their personal information would be kept confidential. The researchers also notified participants that the therapy would be discontinued if patients could not participate due to exacerbation of their physical condition and that they would have the possibility of receiving treatment if they experienced psychological difficulties. Participants were told that their artwork would be photographed and their conversations throughout the process of artwork would be recorded for research purposes. The researchers paid close attention to the circumstances faced by the patients and their family members to ensure that the research process would not be burdensome for them.

\section{Data collection}

The researchers reviewed prior studies on family function and quality of life among terminal cancer patients and their family members, as well as studies on art therapy, to determine how the art therapy experiences of patients and their family members impact family function and quality of life in hospice palliative care. An art therapy intervention program was designed based on the conclusions extracted from those studies regarding patient and family experiences and their psychosocial characteristics. The program was offered to terminal cancer patients and family members in pairs, including a total of four sessions provided once or twice per week. Each session lasted from 20 to 50 minutes depending on the patients' physical condition.

For data collection, a general survey on the characteristics of the patient and family, aspects of nursing and caregiving, and art therapy was prepared, as well as an interview protocol including experiences of terminal cancer diagnosis and treatment, nursing, and caregiving, family relationships and communication, psychological resources, social support, coping ability, wrapping up life and accepting death, and art therapy experience. Non-verbal information such as participants' appearance, emotional state, attitude towards the interview, and surrounding circumstances were recorded in notes and consulted during data analysis. The research was disrupted by un- 
expected situations such as sudden changes in patients' condition and family visits. If patients were not able to participate in an interview in addition to the sessions due to their physical condition, researchers briefly asked about their experiences after the artwork session. Family members were interviewed separately for about 60 minutes in a separate room. All conversations were double-recorded with a dedicated recorder and a cell phone. Interviews were transcribed verbatim based on the recordings. Photos were taken throughout the entire artwork process and were used as visual data, as well as onsite journals and letters for qualitative analysis.

The art therapy intervention program is outlined in Table 1.

\section{Data analysis}

This study investigated the art therapy experiences of patients in hospice palliative care and their family caregivers to understand their experiences through their own lively words.

The researchers tried to understand the experiences of the patients and family caregivers based on on-site journals and notes; the contents of interviews with patients and family members; observations of non-verbal behavior; archives and photos of patients and family members; observations and reports from hospital coordinators, social workers, and assistant workers; and researcher's intuition and self-reflection. The collected data were analyzed using Strauss and Corbin's grounded theory method [20] through the steps of open coding, axial coding, and selective coding of the transcribed indepth interviews as raw data, research memos, and field record notes.

Table 1. Art Therapy Intervention Program.

\begin{tabular}{|c|c|c|}
\hline Day & & Program \\
\hline Day 1 & Screening & $\begin{array}{l}\text { Give participants information about the study, } \\
\text { obtain informed consent form, complete the } \\
\text { questionnaire about family characteristics } \\
\text { (family member) }\end{array}$ \\
\hline Day 2 & Session 1 & Family story: magazine collage journal \\
\hline Day 3 & Session 2 & $\begin{array}{l}\text { Life retrospective notes (family members) } \\
\text { Dignity therapy interview (patient) }\end{array}$ \\
\hline Day 4 & Session 3 & Hand imprinting (patient and family members) \\
\hline Day 5 & Session 4 & $\begin{array}{l}\text { Decorate family memory box (patient and } \\
\text { family members) }\end{array}$ \\
\hline Day 6 & Interview & $\begin{array}{l}\text { Art therapy interview (patient and family } \\
\text { members) }\end{array}$ \\
\hline
\end{tabular}

Open coding is the process of describing, classifying, and naming the concepts using the researcher's theoretical sensitivity and continuing comparisons. Axial coding is the process of reorganizing the relationships of the categories found in the open coding process using the coding paradigm to include categories related to the causal condition, central phenomenon, contextual condition, intervening condition, coping strategy, and the result. Selective coding involves integrating and elaborating the theory by developing a storyline around the core concept arranging it according to the core category, storyline, type analysis, and process analysis.

\section{Validity and reliability of the study}

The researchers made their best efforts to satisfy the evaluative criteria for qualitative research described by Lincoln and Guba [21] which consist of truth value, applicability, consistency, and neutrality.

First, reliability refers to confidence in the truth value of the findings, how vividly the raw data describe the phenomenon, and how accurately the study conveys and interprets participants' experiences. Researchers visited the patients' hospital rooms several times to build rapport with the patients and their family members so that they could comfortably share their thoughts. Applicability involves ensuring the objectivity of the research by collecting and comparing the experiences of the participants until data saturation is reached. The researchers tried to collect as many different experiences as possible during the process of art therapy and interviews by having extensive conversations with participants. Participants' interviews were double-recorded to ensure consistency, and two psychology professors and one art therapy professor provided advice to ensure the consistency of the entire research process. Lastly, neutrality relates to ensuring objectivity so that the findings of a study are not shaped by the researchers' biases, motivations, or interests. The researchers used the inductive method to identify hypotheses from the collected data, repeatedly reading the raw data to prevent researcher bias, and conducted an in-depth analysis of the field record notes and art therapy contents to identify the meanings of the patients and families' experience. Errors from researchers' individual subjective interpretation were minimized by peer review from an expert with a doctorate in art therapy, a clinical psychologist, 
and a hospice art therapist.

\section{RESULTS}

\section{Characteristics of participants}

The participants in this study were patients admitted to hospice palliative care units and their family members, mostly including patients' primary caregivers, parents, spouses, and children who visited the patients. A total of 17 participants from six families were included in the study, including pairs of patients and primary caregivers who attended the sessions regularly and other family members who occasionally attended the programs. The six patients were aged between 38 and 77 years (average age, 62.5 years), all of whom were married, and six of whom were Protestant Christians. Two had been diagnosed with breast cancer, two with lung cancer (one of them with brain hemorrhage), one with pancreatic cancer, and one with colorectal cancer. The duration of treatment ranged from 0 to 10 years, implying varying disease experiences. The duration of hospice palliative care ranged from less than 2 weeks to 6 months. Three patients (no. 1, 2, and 3) were totally de-

Table 2. Family Characteristics.

\begin{tabular}{|c|c|c|c|c|c|c|c|c|c|c|}
\hline $\begin{array}{c}\text { Family } \\
\text { member } \\
\text { number }\end{array}$ & $\begin{array}{c}\text { Participant } \\
\text { name }\end{array}$ & Gender & $\begin{array}{l}\text { Age } \\
\text { (yr) }\end{array}$ & $\begin{array}{c}\text { Relationship } \\
\text { with the } \\
\text { patient }\end{array}$ & $\begin{array}{c}\text { Marital } \\
\text { status }\end{array}$ & Residence & Religion & $\begin{array}{c}\text { Family } \\
\text { relationship } \\
\text { (before } \\
\text { disease onset) }\end{array}$ & $\begin{array}{c}\text { Family } \\
\text { relationship } \\
\text { (after } \\
\text { disease onset) }\end{array}$ & $\begin{array}{l}\text { Participant } \\
\text { (family } \\
\text { member) }\end{array}$ \\
\hline 01 & A & $\mathrm{F}$ & 60 & Mother & Married & Living apart & Protestant & Very good & Very good & Husband \\
\hline 01 & B & $\mathrm{F}$ & - & Mother-in-law & Married & Living apart & Protestant & Very good & Very good & Husband \\
\hline 01 & C & $F$ & 7 & Daughter & - & Cohabitation & Protestant & Very good & Very good & $\begin{array}{l}\text { Parents, } \\
\text { daughter }\end{array}$ \\
\hline 02 & $D$ & F & 70 & Spouse & Married & Cohabitation & Protestant & Very good & Very good & Husband, son \\
\hline 03 & $E$ & $\mathrm{~F}$ & 58 & Spouse & Married & Living apart & Catholic & Very good & Very good & Parents, son, \\
\hline 03 & $\mathrm{~F}$ & $\mathrm{~F}$ & 20 & Daughter & Unmarried & Cohabitation & Catholic & Very good & Very good & daughter \\
\hline 04 & G & $F$ & 45 & Daughter & Married & Living apart & Protestant & Good & Very good & Husband, son \\
\hline 05 & $\mathrm{H}$ & F & 70 & Spouse & Married & Cohabitation & Protestant & Normal & Very good & Husband \\
\hline 05 & | & $F$ & - & Son-in-law & Married & Living apart & Protestant & Very good & Very good & Parents, son, \\
\hline 05 & $J$ & $\mathrm{~F}$ & - & Daughter & Married & Living apart & Protestant & Very good & Very good & daughter \\
\hline 06 & K & F & 34 & Daughter & Married & Cohabitation & Protestant & Very good & Verygood & $\begin{array}{l}\text { Husband, } \\
\text { daughter }\end{array}$ \\
\hline
\end{tabular}

Table 3. Patient Characteristics.

\begin{tabular}{|c|c|c|c|c|c|c|c|c|c|c|}
\hline $\begin{array}{l}\text { Patient } \\
\text { number }\end{array}$ & $\begin{array}{l}\text { Participant } \\
\text { name }\end{array}$ & Gender & $\begin{array}{l}\text { Age } \\
\text { (yr) }\end{array}$ & $\begin{array}{l}\text { Marital } \\
\text { status }\end{array}$ & Religion & $\begin{array}{c}\text { Cancer } \\
\text { diagnosis }\end{array}$ & $\begin{array}{l}\text { Treatment } \\
\text { duration }\end{array}$ & $\begin{array}{l}\text { Hospice care } \\
\text { duration }\end{array}$ & $\begin{array}{l}\text { Activities of } \\
\text { daily living }\end{array}$ & $\begin{array}{c}\text { Recognition } \\
\text { of disease } \\
\text { state as } \\
\text { terminal }\end{array}$ \\
\hline 01 & L & $\mathrm{F}$ & 38 & Married & Protestant & Breast cancer & 9 months & $\begin{array}{l}2 \text { weeks to } \\
1 \text { month }\end{array}$ & $\begin{array}{l}\text { Totally } \\
\text { dependent }\end{array}$ & Yes \\
\hline 02 & M & M & 77 & Married & Protestant & $\begin{array}{l}\text { Lung cancer/brain } \\
\text { hemorrhage }\end{array}$ & 2 years & $3 \sim 6$ months & $\begin{array}{l}\text { Totally } \\
\text { dependent }\end{array}$ & No \\
\hline 03 & N & $\mathrm{F}$ & 51 & Married & Catholic & Breast cancer & 10 years & $3 \sim 6$ months & $\begin{array}{l}\text { Totally } \\
\text { dependent }\end{array}$ & Yes \\
\hline 04 & 0 & M & 73 & Bereavement & Protestant & Lung cancer & 10 months & $\begin{array}{l}\text { Less than } \\
2 \text { weeks }\end{array}$ & $\begin{array}{l}\text { Partially } \\
\text { dependent }\end{array}$ & Yes \\
\hline 05 & P & M & 75 & Married & Protestant & Pancreatic cancer & None & $\begin{array}{l}2 \text { weeks to less } \\
\text { than } 1 \text { month }\end{array}$ & Independent & Yes \\
\hline 06 & $Q$ & $\mathrm{~F}$ & 61 & Divorce & Protestant & Colorectal cancer & 19 months & $\begin{array}{l}\text { More than } 2 \\
\text { weeks to less } \\
\text { than } 1 \text { month }\end{array}$ & $\begin{array}{l}\text { Totally } \\
\text { dependent }\end{array}$ & Yes \\
\hline
\end{tabular}


pendent on their family members or caregivers for activities of living, as they were not able to independently sit, eat meals, or move around. Two patients (no. 4 and 5) suddenly developed aggravated symptoms while at the hospital, while another pa- tient saw her symptoms progress slowly (no. 6). Many of the patients (no. 1, 2, 3, and 4) had cognitive decline due to brain metastasis, and two of them (no. 2 and 4) showed significant impairments in speech and reactions to external stimuli. Most

Table 4. Open Coding.

\begin{tabular}{|c|c|}
\hline Subcategory & Category \\
\hline $\begin{array}{l}\text { - The whole family was worried after cancer diagnosis } \\
\text { - Patients underwent surgery due to the recurrent metastasis even after chemotherapy } \\
\text { - Surgery made them regretful } \\
\text { - Patients gave up trying to prolong their lives } \\
\text { - Family's last trip }\end{array}$ & $\begin{array}{l}\text { The entire family suffered from an inner struggle } \\
\text { after the cancer diagnosis }\end{array}$ \\
\hline $\begin{array}{l}\text { - There was nothing the family could do, so we came to the hospice } \\
\text { - Afraid of hospitalization in the hospice ward } \\
\text { - Hospice is a space to relieve pain rather than cure the illness } \\
\text { - It is inconvenient and burdensome to move to another hospital or unit } \\
\text { - They became accustomed to the hospice services }\end{array}$ & Dealing with pain rather than treatment \\
\hline $\begin{array}{l}\text { - They recognized the patient's symptoms that they did not understand before } \\
\text { - The patient suffered alone from deteriorated pain } \\
\text { - The patient suffered from ascites } \\
\text { - The patient developed paralysis symptoms } \\
\text { - Eating problems and lethargy } \\
\text { - Delirium } \\
\text { - While suffering, the patient refused others' assistance }\end{array}$ & Difficulty moving one's body independently \\
\hline $\begin{array}{l}\text { - The patient forgot about the illness due to impaired memory } \\
\text { - The patient became a completely different person after suffering }\end{array}$ & Forgetting one's own features \\
\hline $\begin{array}{l}\text { - It is difficult for the patient to accept their terminally ill status } \\
\text { - Guilty feeling } \\
\text { - Suffered from a worrisome heart } \\
\text { - Conversation breakdown among family members } \\
\text { - Regret that patients did not spend time well with their family } \\
\text { - Conflicts within family members } \\
\text { - The family had more hardship than the dying person }\end{array}$ & Difficulty letting a family member go before death \\
\hline $\begin{array}{l}\text { - The family had inner struggles due to the patient } \\
\text { - Cancer in the son and daughter disbanded their family } \\
\text { - The stress of care giving also made family members ill } \\
\text { - The cancer of the patient caused children concern or fear } \\
\text { - They had to endure financial hardship } \\
\text { - The issue of domestic violence } \\
\text { - The stress caused by the death of a family member }\end{array}$ & Struggling with pre-existing family problems \\
\hline $\begin{array}{l}\text { - The poor health condition of the family made caregiving more difficult } \\
\text { - Family members had difficulty in their first caregiving experiences, so they tried to learn know-how }\end{array}$ & Caregiving for the sick also needs know-how \\
\hline $\begin{array}{l}\text { - Natural distancing from other people due to caring for a cancer patient } \\
\text { - Forgetting one's pain and placing one's mind at ease } \\
\text { - Reliving previous memories and looking back at one's life } \\
\text { - Leaving the patient's last memento and bidding farewell } \\
\text { - Realizing the meaning and happiness of being with family }\end{array}$ & $\begin{array}{l}\text { Natural distancing from other people } \\
\text { Art therapy work with family members is } \\
\text { meaningful and makes them feel happy }\end{array}$ \\
\hline $\begin{array}{l}\text { - The patient was encouraged by the support of surrounding people } \\
\text { - The patient was empowered by support from fellow patients } \\
\text { - The patient became empowered through the help of the surrounding people } \\
\text { - They became interested in volunteer activities }\end{array}$ & $\begin{array}{l}\text { Encouragement from the assistance of } \\
\text { surrounding people }\end{array}$ \\
\hline
\end{tabular}


Table4. Continued.

\begin{tabular}{lc}
\hline \multicolumn{1}{c}{ Subcategory } & Category \\
\hline - The illness made family relationships closer than ever & Closer relationships with family members during \\
- Familly members gave thanks to the patients who endured suffering for their family & Despite not wanting death, hoping for it to be \\
- Family members considered the patients, wishing them comfort for the rest of their life & comfortable \\
- Feeling the love of family & It was hard for family members to accept the death of the patient \\
- I don't want death, but I want a comfortable death (ambivalence) & Acceptance of the laws of nature \\
- Stabilization of the patient who fears death & \\
- Thptying their minds and making their hearts ready & \\
- They changed their mind as patients had near-death experiences & \\
- They found it difficult, but accepted the laws of nature &
\end{tabular}

of the patients were aware that they had been transferred to the hospice palliative care unit due to aggravated symptoms and discontinuation of treatment and recognized that they were approaching death, but one patient (no. 2) had not been informed of her status by her family members; this patient showed extreme anxiety and cried whenever she was transferred to a different environment (Table 2).

The primary family caregivers were all women aged between 20 and 70 years (average age, 45.5 years) who were mothers, wives, or daughters of the patients. All of them, except for a caregiver who was a married child of a patient, lived with the patient. Eleven of the family members were Protestants. The duration of caregiving was between 6 months and 2 years; some caregivers had provided care throughout the entire period, while others had hired professional caregivers for workor health-related reasons. The family caregivers felt less burden if they had support from others, while those who did not receive any support experienced negative impacts on their own health (Table 3).

\section{Open coding}

The analysis of the interviews with patients and their family members who participated in the art therapy intervention program at the hospice palliative care unit generated 154 open coding concepts, 56 subcategories, and 13 categories (Table 4).

\section{1) Open coding analysis results}

The 13 categories generated from the open coding analysis were: The whole family suffers from an inner struggle after the cancer diagnosis; dealing with pain rather than treatment; difficulty moving one's body independently; forgetting one's own features; difficulty letting a family member go before death; struggling with pre-existing family problems; caregiving for the sick also needs know-how; natural distancing from other people; art therapy work with family members is meaningful and makes them feel happy; encouragement from the assistance of surrounding people; closer relationships with family members during illness; despite not wanting death, hoping for it to be comfortable; and acceptance of the laws of nature.

Through this study, the researchers aimed to understand the struggles against illness and caregiving experiences of patients and their family members through in-depth interviews and analyses of family relationships and dynamics, art therapy experiences, and changes over the course of the illness. First, regarding the struggles and caregiving experiences of patients and their family members, the patients and their family members selected hospice palliative care based on a realization of the limits of treatment and caregiving, after suffering from psychological difficulties due to anxiety and regret over the cancer diagnosis and surgery. The patients expressed psychological pain caused by their negative perceptions of hospice care as a place where patients go to die and simply have their pain relieved instead of receiving treatment, and indicated that their psychological suffering was not relieved by the reduced physical pain. They felt the need for end-of-life psychological treatment and consulting. The longer they remained in hospice care, the worse their physical symptoms became, and they found it difficult to communicate with family members 
due to dementia and cognitive decline. Although family members tried to take care of the patients based on their physical status, the aggravation of the patients' symptoms and caregivers' lack of experience caused them considerable stress. The burden of caregiving was different in each family depending on the physical and cognitive status of the patient. Family members suffered from conflicts, guilt, lack of communication, and preliminary grief, experiencing psychological hardships on top of pre-existing family issues such as domestic violence, illness, and financial hardship. Family members also experienced weakening social support as they became distanced from friends and family while they took care of the patient. The pre-existing issues of family members especially added to the psychological burdens faced by family caregivers, diminishing the family's ability to cope with issues and weakening family function, leading to a lower quality of life for patients and their families. The initial consultation session during the art therapy program drew out the issues that patients and their family members experienced, helping us to understand how family relationships and dynamics, pre-existing family relationships, patients' and family members' attitudes toward death, family functions, problem-solving, and coping ability impacted their overall quality of life. The art therapy also allowed patients and families to temporarily forget about their illness, relax, reminisce about memories with family, and $\mathrm{re}^{-}$ flect upon their lives. Family members were given the chance to prepare for the patient's death by creating their last artwork in life together and found it meaningful to have quality family time in their remaining time with the patients. Patients and family caregivers naturally paid attention to people around them and felt empowered by the support and help from fellow patients, family, and social workers. Patients and their family members became more intimate as they exchanged thoughts during art therapy sessions. Family members showed more understanding and respect as they conversed with patients about death. Family members were willing to let the patients go comfortably, while patients accepted death as a natural part of life, although they were faced with conflicts with family members. Art therapy in hospice palliative care improved mutual understanding and solidarity among family members during the process of collaboration and helped them express their grief and anxiety about losing a family member to death. Art therapy also helped them reflect on the meaning of life and learn how precious they were to each other, building stronger bonds with their loved ones. This process served as an opportunity to overcome the fear of death and loss, to express and confirm love and appreciation towards family, and to prepare for death while spending meaningful family time during the time that remained.

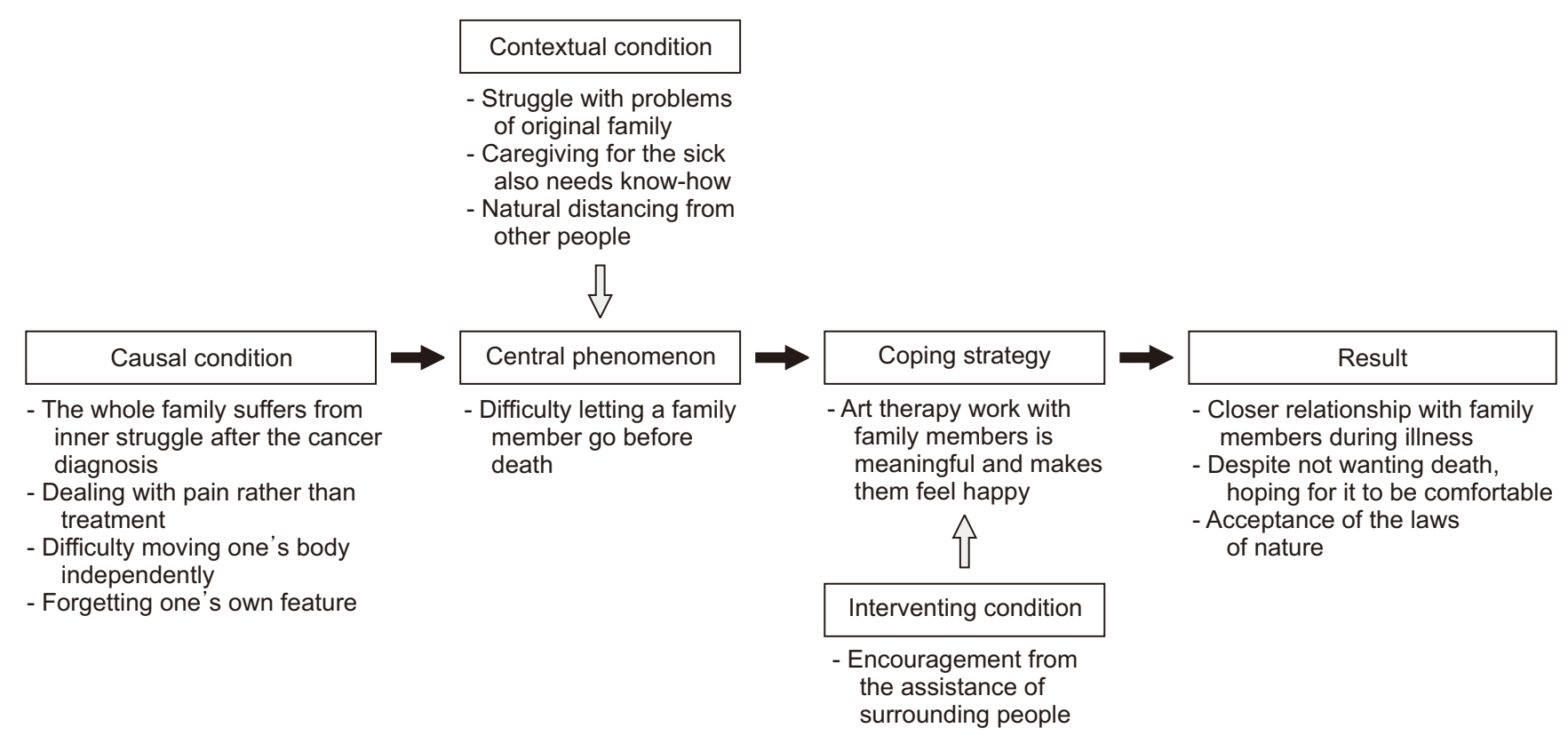

Figure 1. Paradigm model. 


\section{Axial coding}

Axial coding was performed to explain the relationships among the categories derived by open coding of patients' and family members' experiences in hospice palliative care and the art therapy intervention program.

The paradigm model describes the relationships among the categories by connecting them to a single axis composed of causal conditions, central phenomenon, contextual conditions, intervening conditions, coping strategy, and results (Figure 1).

Causal conditions represent the cause of the central phenomenon (difficulty letting a family member go before death), and included the following subcategories: the whole family suffers from an inner struggle after the cancer diagnosis, dealing with pain rather than treatment, difficulty moving one's body independently, and forgetting one's own features. The central phenomenon of the study was difficulty letting a family member go before death. The contextual conditions were found to be as follows: struggling with pre-existing family problems, caregiving for the sick also needs know-how, and natural distancing from other people. The art therapy intervention was planned as a coping strategy for psychosocial care for patients and their family members, and turned out to be "meaningful and makes them feel happy". The intervening condition was

Table 5. Types of "Acceptance of Death, although It Is Hard to Let a Family Member Go Before Death".

\begin{tabular}{|c|c|c|c|c|c|}
\hline \multirow{2}{*}{$\begin{array}{r}\text { Condition } \\
\text { Causal condition }\end{array}$} & \multirow{2}{*}{$\begin{array}{l}\text { Category } \\
\text { The whole family suffers from an } \\
\text { inner struggle after the cancer } \\
\text { diagnosis }\end{array}$} & \multicolumn{4}{|c|}{ Property and dimensional analysis } \\
\hline & & Attitude: skeptical & Skeptical-passive & Active & Active \\
\hline & $\begin{array}{l}\text { Dealing with pain rather than } \\
\text { treatment }\end{array}$ & Attitude: negative & Negative & Positive & Positive \\
\hline & $\begin{array}{l}\text { Difficulty moving one's body } \\
\text { independently }\end{array}$ & Condition: hard & Hard & Moderate-hard & Moderate \\
\hline & Forgetting one's own features & Condition: hard & Moderate-hard & Moderate & Weak \\
\hline Central phenomenon & $\begin{array}{l}\text { Difficulty letting a family member } \\
\text { go before death }\end{array}$ & Condition: hard & Moderate-hard & Weak-moderate & Weak \\
\hline \multirow[t]{3}{*}{ Contextual condition } & $\begin{array}{l}\text { Struggle with problems of } \\
\text { original family }\end{array}$ & Strength: hard & Moderate-hard & Moderate & Weak \\
\hline & $\begin{array}{l}\text { Caregiving for the sick also } \\
\text { needs know-how }\end{array}$ & Strength: hard & Moderate-hard & Moderate & Weak \\
\hline & $\begin{array}{l}\text { Natural distancing from other } \\
\text { people }\end{array}$ & Strength: hard & Moderate-hard & Moderate & Weak \\
\hline \multirow[t]{2}{*}{ Intervening condition } & Encouragement from the & Supporter: less & Less-moderate & Moderate-massive & Massive \\
\hline & $\begin{array}{l}\text { assistance of surrounding } \\
\text { people }\end{array}$ & $\begin{array}{l}\text { Support degree: } \\
\text { weak }\end{array}$ & Weak-moderate & Moderate-hard & Hard \\
\hline \multirow[t]{2}{*}{ Coping strategy } & Art therapy work with family & Attitude: negative & Negative-positive & Positive & Positive \\
\hline & $\begin{array}{l}\text { members is meaningful and } \\
\text { makes them feel happy }\end{array}$ & Quality: lack & Lack-moderate & Moderate & Enough \\
\hline \multirow[t]{3}{*}{ Result } & $\begin{array}{l}\text { Closer relationships with family } \\
\text { members during illness }\end{array}$ & Attitude: negative & Negative-positive & Positive & Positive \\
\hline & $\begin{array}{l}\text { Despite not wanting death, } \\
\text { hoping for it to be comfortable }\end{array}$ & Attitude: refusal & Refusal-conflict & Conflict-acceptance & Acceptance \\
\hline & Acceptance of the laws of nature & Attitude: negative & Negative & Positive & Positive \\
\hline \multirow[t]{6}{*}{ Type analysis } & Participants & $01-L$ & $01-A$ & $01-B$ & $05-P$ \\
\hline & & 02-M & $03-N$ & $04-G$ & 05- H \\
\hline & & 02-D & 03-E & $05-J$ & $06-Q$ \\
\hline & & $03-F$ & & & $06-K$ \\
\hline & & $04-0$ & & & \\
\hline & Type classification & $\begin{array}{l}\text { Negative } \\
\text { rejection type }\end{array}$ & $\begin{array}{l}\text { Passive } \\
\text { management type }\end{array}$ & $\begin{array}{l}\text { Active } \\
\text { management type }\end{array}$ & $\begin{array}{l}\text { Supportive } \\
\text { acceptance type }\end{array}$ \\
\hline
\end{tabular}


encouragement from the assistance of surrounding people. The coping strategy resulted in closer relationships with family members during illness; despite not wanting death, hoping for it to be comfortable; and acceptance of the laws of nature.

\section{Selective coding}

Selective coding was the final step of identifying the core category in order to integrate and elaborate all of the other categories around it. The core category found in this study was "acceptance of death, although it is hard to let a family member go".

\section{Type analysis}

Type analysis involves the standardization of recurring relationships in each category by a repeated comparison of the hypotheses of the relationships of each category with the references. The core category of "acceptance of death, although it is hard to let a family member go" was analyzed as having four types (Table 5).

1) Negative rejection type: Participants of this type were skeptical about the treatment process and had negative views on hospice palliative care. Patients of this type had aggravated physical and cognitive symptoms, causing high stress for family caregivers, and found it almost impossible to carry out meaningful artwork with family members. These patients and their family members suffered from psychological hardships due to family conflicts and weak social support.
2) Passive management type: Participants in this group had a skeptical and passive attitude regarding terminal cancer diagnosis and treatment. Participants had pre-existing problems with their family members and did not have much help or support from family and friends, even though they found caregiving to be difficult. Family members did not accept the patients' approaching death well due to emotional distance. They seemed to have difficulty providing emotional support or connecting with the patients, although they tried to address issues related to caregiving.

3) Active management type: Participants of this type were proactive in the diagnosis and treatment process, as well as in the selection of hospice palliative care. These families previously had conflicts among their members, but those conflicts did not affect the current relationship. They were very engaged in caregiving, with support and help from other family members, caregivers, and social workers whom they met in the hospice unit, overcoming the lack of help and support from friends and family.

4) Supportive acceptance type: Participants in this group were proactive in the diagnosis and treatment process, as well as in selecting hospice palliative care for the patient. Patients maintained relatively good physical and cognitive function, and the patients and family members exchanged their thoughts and feelings well. The entire family acted as a team to provide care and support for the patient, allowing the patient to be comfortable and emotionally stable.

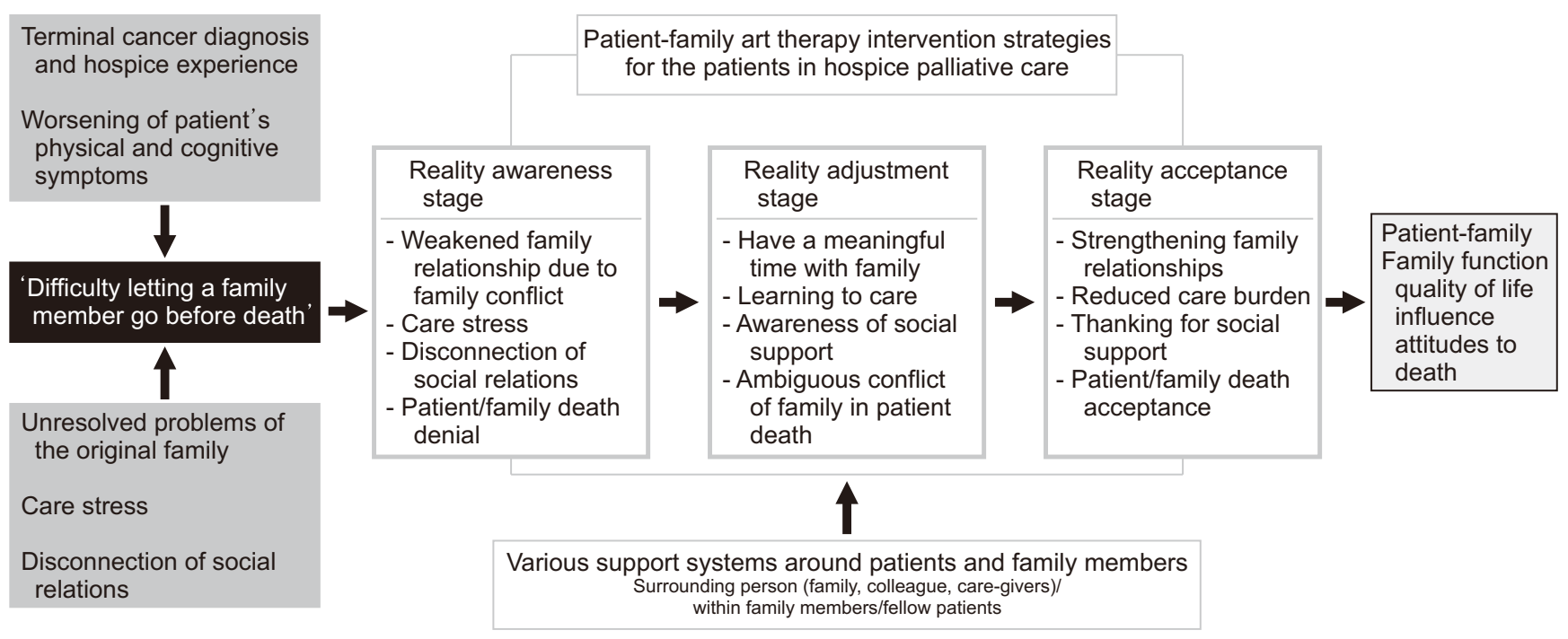

Figure 2. Process of "acceptance of death, although it is hard to let a family member go". 


\section{Process analysis}

This study found that the process of "acceptance of death, although it is hard to let a family member go before death" consisted of the reality-awareness stage, the reality-adjustment stage, and the reality-acceptance stage during the art therapy intervention program (Figure 2).

1) During the reality awareness stage, patients and their family members realized their current state, involving difficulties due to family conflicts, a lack of conversation, stress from caregiving, distancing from other people, and accepting the patient's impending death.

2) In the reality adjustment stage, patients and their family members adjusted and adapted to their situation. Patients and their family caregivers spent time together meaningfully while creating artwork, and caregivers learned how to take care of the patient and realized the support and help they received from others. This is the stage in which family members adapted to the reality of the patient's approaching death no matter how difficult it was, after overcoming their ambivalence.

3) During the reality acceptance stage, patients and their family members felt closer to each other through art therapy and appreciated the help they received from other people. Patients and family members bonded while fighting against illness, becoming closer with each other, understanding each other's situation, and being considerate, ultimately learning to prepare for and accept that the patient will die.

The use of the art therapy intervention strategy helped $\mathrm{pa}^{-}$ tients spend more quality time with their family members during their remaining lifespan and positively affected family function, quality of life, and attitudes towards death as part of the process of accepting death, despite the difficulty of letting go of a family member before death.

\section{DISCUSSION}

Art therapy is often used as a medium for psychological support and emotional caregiving for patients and their families as hospice palliative care services have become more widely used in recent years. However, art therapy programs often approach patients and their family members without fully understanding their psychological difficulties due to a lack of research on their actual dynamics and psychological characteristics. The purpose of this study was to understand the struggles against illness of terminal cancer patients and the caregiving experiences of their family members and to probe the impact of an art therapy intervention on family function and quality of life in a hospice palliative care unit.

This study found that patients in hospice palliative care and their family members experienced a diverse range of psychological issues, including patients' fear of death when they move into the hospice palliative care center after halting curative treatment, unresolved mental suffering while dealing with physical pain, family members' feelings of guilt for the patient' s illness, frustration, helplessness, depression, a sense of loss for having to let go of a family member, and ambivalence before the patient's death. Family caregivers were overwhelmed by the caregiving they had to provide for their sick family member but tried their best to learn how to look after the patient and help the patient stay comfortable for their remaining time on earth. These findings are in line with studies suggesting that family members play a significant role in patients' treatment and recovery, proactively participating in many ways to overcome difficulties [22], and that patient care is affected by how well families cope with the stress of illness [23]. By studying patients and family caregivers in pairs, it was also found that patients and their family members often held different views about their illness experiences. Patients expected both physical and psychological care when they were admitted to hospice palliative care units, while family caregivers were both physically and psychologically exhausted by their caregiving activities. Such differences can cause imbalances in family relationships and functions, which may interfere with patient-family communication and lead to invisible conflicts. The extreme stress, helplessness, and frustration caused by the fear of losing a family member felt by the family members in this study were similar to the results presented in an earlier study showing that aggravated physical symptoms followed by the increasing burden on family members from caregiving had negative impacts on family members' physical and mental status [24]. So far, the hardships experienced by family members have not yet received much attention given the tendency for patient-focused treatment; however we found that taking care of family caregivers is extremely important since family support plays 
an essential role in patient care. Therefore, counseling on how to understand and approach coping with death, education on death, and family relationship skills are required in hospice palliative care for terminal cancer patients and their caregivers [25], and understanding the pain experienced by patients and their family members enables us to offer holistic and effective care [26].

Previous studies on art therapy as part of hospice palliative care in Korea and abroad focused on providing psychological and social care for either terminal cancer patients or their family members, but rarely provided care for patients and family members together. This study explored the experiences of patients and their family members who participated in the art therapy intervention program and discussed the outcomes in comparison with preceding studies.

The participants in this study experienced increased positive communication, such as listening and showing respect to each other, through their exchanges of thoughts and feelings during collaboration in artwork, which is consistent with the findings of another study that reported improved family intimacy and family relationships [27]. Art therapy is also a process in which patients at the end-stage of life prepare for their expected loss and spend their remaining time in a meaningful way [9], and patients create artwork that will be left as a family keepsake [28], but the intervention program in this study was different in that patients and family members collaborated in the process and that they actually worked on the artwork with the purpose of creating a keepsake based on a more realistic understanding and approach toward the patient's death. The conclusions of this study are also similar to those of a previous study, which suggested that the process of free creation of artwork provided psychological stability by dispersing negative feelings such as patient-family conflicts, ambivalence, regret, and concerns [29], especially insofar as both patients and family members engaged in retrospection on life, appreciated their lives through the process of artwork, and accepted death as a natural part of life [30]. These findings are also similar to those of studies suggesting that family members made their best efforts to take care of patients and received consolation and support from social workers in hospice palliative care [9], except that the participants in this study felt more support and sympathy from fellow patients and their family members. One of the participants, after experiencing emotional support and care, decided to work as a volunteer in hospice palliative care, which represents the self-expanding experience of a family member from the object of receiving care to a subject of providing care.

This art intervention program, which provided social and psychological support for patients and their family members in hospice palliative care, was therapeutically meaningful for multiple reasons. First, it allowed participants to express emotions such as anxiety and ambivalence over conflicts and death during the process of artwork that were difficult to verbalize. Second, the artwork created in collaboration with family members was tangible and perpetual object and could console remaining family members after the patient's death as a keepsake. Third, the visual image of the artwork helped patients and family members reflect on their lives and provided an opportunity to look back on their lives. Fourth, the process of creating artwork was a perceptual and kinesthetic activity in which the activity of making shapes and handling materials itself provided joy and a sense of satisfaction and self-efficacy, thereby improving the quality of life of patients and their family members faced with physical limits and isolation.

The core category of patients' and family members' experiences found in this study was "acceptance of death, although it is hard to let a family member go", and the types of attitudes toward death based on the patients' struggle with illness and family members' caregiving experiences were negative rejection, passive management, active management, and supportive acceptance. Patients and their family members also experienced the process of perceiving, adjusting, and accepting reality through the art therapy intervention program. It was proven that the art therapy intervention program had a positive impact on family function and quality of life among patients in hospice palliative care and their family members, changing their attitudes toward death.

This study aimed to probe patients and their family members as a system, to understand family function and quality of life through the lens of family dynamics, and to convey the vivid experiences of patients and family through in-depth interviews and art therapy. This study also provided theoretical foundations for art therapy in hospice palliative care for patients and their family members using the grounded theory method. 


\section{CONFLICT OF INTEREST}

No potential conflict of interest relevant to this article was reported.

\section{ORCID}

Sungeun Park, https://orcid.org/0000-0002-6790-1108

Hyunjoo Song, https://orcid.org/0000-0002-7199-6461

\section{AUTHOR'S CONTRIBUTIONS}

Conceptualization \& Methodology: SP. Data curation \& Formal analysis: SP. Funding acquisition: None. Investigation: SP. Project administration \& Supervision: HS. Resources \& Software: SP. Validation: SP, HS. Writing - original draft: SP. Writing - review \& editing: SP, HS.

\section{SUPPLEMENTARY MATERIALS}

Supplementary materials can be found via https://doi. org/10.14475/kjhpc.2020.23.4.183.

\section{REFERENCES}

1. Choi BR. Hope and post-traumatic growth in family caregivers of cancer patients: focusing on family function [master's thesis]. Seoul: Sangmyung Univ.; 2018. Korean.

2. Kim GS. A study on the relationship between perceived family support and quality of life of cancer patients [master's thesis]. Daejeon: Daejeon Univ.; 2003. Korean.

3. Kwon IG, Hwang MS, Kwon KM. Quality of life of the terminal cancer patients receiving home care nursing. J Korean Clin Nurs Res 2008;14:103-14.

4. Ha SH. Predicting caregiver's quality of life with terminal cancer patient [master's thesis]. Seoul: Ewha Womans Univ.; 2004. Korean.

5. Walsh SM, Weiss S. Online exclusive: art intervention with family caregivers and patients with cancer. Oncol Nurs Forum 2003;30:E115-20.

6. Malchiodi CA. Art therapy and health care. New York:Guilford Press;2013.

7. Nainis N, Paice JA, Ratner J, Wirth JH, Lai J, Shott S. Relieving symptoms in cancer: innovative use of art therapy. J Pain Symptom Manage 2006;31:162-9.

8. Noh JA, Geum WS, Kim NY, Choi MY, Park EJ, Kim JH, et al. Satisfaction for art therapy in the cancer patients and their family: An experience of Y Cancer Center. Family and Counselling 2016;6:77-86.

9. Dan JS. Hermeneutic phenomenological understanding on the lived experience of hospice caregiver's anticipatory grief through art therapy [master's thesis]. Seoul: Seoul Women's Univ.; 2013. Korean.

10. Park SN. Hermeneutic phenomenological understanding on the lived experience of a hospice patient's forgiveness related to family conflict through art therapy [master's thesis]. Seoul: Seoul Women's Univ.; 2013. Korean.

11. Kennett CE. Participation in a creative arts project can foster hope in a hospice day centre. Palliat Med 2000;14:419-25.

12. Lin MH, Moh SL, Kuo YC, Wu PY, Lin CL, Tsai MH, et al. Art therapy for terminal cancer patients in a hospice palliative care unit in Taiwan. Palliat Support Care 2012;10:51-7.

13. Gabriel B, Bromberg E, Vandenbovenkamp J, Walka P, Kornblith AB, Luzzatto P. Art therapy with adult bone marrow transplant patients in isolation: a pilot study. Psychooncology 2001;10:114-23.

14. Thomas G, Kennedy J. Art therapy and practice in palliative care. European J Palliat Care 1995;2:120-3.

15. Thompson BE, Neimeyer RA. Grief and the expressive arts : practices for creating meaning. NY:Routledge;2014.

16. Jones F, Warren A, McElroy S. Home-based art therapy for older adults with mental health needs: Views of clients and caregivers. Art Therapy 2006;23:52-8.

17. Katherine $\mathrm{H}$. The role of art therapy in hospice: An understanding of the grief process for caregivers [master's thesis]. Indianapolis, IN: Indiana Univ.; 2014. American.

18. Safrai MB. Art therapy in hospice: A catalyst for Insight and healing. Art Therapy 2013;30:122-9.

19. Hawkin N. A new outlook for rehabilitation: creative art therapy. Caring 1993;12:80, 82, 84.

20. Strauss A, Corbin J. Basis of qualitative research: Grounded theory procedure and techniques. 2nd ed. Newbury Park, CA: SAGE; 1990.

21. Lincoln YS, Guba EG. Naturalistic inquiry. Newbury Park. CA: SAGE; c1985.

22. Northous $L$. The impact of cancer on the family: An overview. Int J Psychiatr Med 1985;14:215-42.

23. Park YH, Hyeon HJ. Caregiver burden and family functioning of cancer patient. J Korean Acad Soc Adult Nurs 2000;12:384-95. 
24. Nijboer C, Tempelaar R, Sanderman R, Triemstra M, Spruijt RJ, van den Bos GA. Cancer and caregiving: the impact on the caregiver's health. Psychooncology 1998;7:3-13.

25. Yang ES. Hospice caring experience of family members for terminal cancer patient : Base on Van-Manen's hermeneutic phenomenological approach [dissertation]. Seoul: Sungkyunkwan Univ.; 2019. Korean.

26. Kim HJ, Ko SJ. The exploration of psychological needs of terminal cancer patients under palliative care. Proceeding of the Korean Psychological Association; 2013 Aug 22-24; Daejeon, Korea. Seoul: Korean Psychological Association; 2013. p. 297-8.

27. Ku MR. The effects of the family art therapy on family communication, mutual respect and family strengths [dissertation]. Seoul: Baekseok Univ.; 2007. Korean.

28. Choi YS. Hermeneutic phenomenological understanding on lived experience of art therapists who performed art therapy with cancer patients and their families in hospice palliative care [master's thesis]. Seoul: Seoul Women's Univ.; 2017. Korean.

29. Choi JS. Art therapy case studies on palliative care [master's thesis]. Seoul: Dongguk Univ.; 2013. Korean.

30. Kim SH, Kim SH. The effect of clinical art therapy on pain relief and life quality of hospice patients. J Korean Acad Clin Art Ther 2014;9:44-50. 